\title{
Always be Selling-Even on the Job
}

\author{
C. Kenneth Meyer, Marlene Heuertz, Jeffrey A. Geerts, \& Lance J. Noe \\ Drake University \\ USA
}

\begin{abstract}
The era of the "dual and triple" job family is not only reflected in the "mantra" of the $21^{\text {st }}$ Century workplaceflexibility, flexibility, flexibility, but often poses questions on what commercial and promotional activities employees are permitted to bring into the work environment. One of the major problematic workplace activities that is positively countenanced by some, but negatively viewed by other co-workers is the practice of "solicitation on the job." Although this non-experimental, case study, design is written about a practice that is more severe than selling promotional sale products, such as pastries, cookie dough, cookies, candy, and popcorn, for youth clubs (scouts) and other nonprofit or charitable community, fraternal or faith based 501(c)(3) organizations, it details the predicament faced by the executive director Derek Spiegel of the Morningside Rural Electrical Cooperative (MREC), when Felicia Lynn, a long-time employee, has gone well beyond what might be considered permissible, by promoting, selling, and delivering Debbie Green's Beauty Supplies while on the clock. As the case unfolds, office politics and professional decorum come into play, and the dilemma of not having a wellcrafted and published "solicitation policy" for MREC becomes evident. The problem is further exacerbated by disagreement among the board members on what the governing policy on solicitation should entail. In conclusion, the director turns to the Society for Human Resource Management (SHRM) for recommendations on a "Model Solicitation Policy." The Case concludes with an artistically written and managerially challenging set of Questions and Instructions.
\end{abstract}

Keywords: Human Resource Management, Solicitation, Employee Conduct, Model Personnel Policy, Board of Directors, Leadership, Employee Discipline

\section{Recommended Courses:}

Human Resource Management, Case Studies in Management, Leadership, State and Local Government, Ethical Decision Making, Public Administration, Business Management

Morningside Rural Electrical Cooperative (MREC) has supplied electricity to its customers for nearly one century and has done so in a cost-effective way. The old timers in Northrup, a regional economic and financial hub, speak about the days when electrification was first brought through the mountains and the difficult time they had putting in the foundation for the high voltage towers in rock and granite which now jettisoned from the landscape like a "forest of steel." They also reminisced about the route which the electric lines took from the Boulder Dam (Hoover Dam) outside Las Vegas, Nevada, to the desert highlands. Electricity was such a novelty. It took nearly 40 years for twenty-five percent of the population in the United States to have electric power in their backyards.

Derek "Lar" Spiegel, the executive director of MREC was a well-liked member of the Northrup community and was known for his probity, integrity, and conviviality. He managed the cooperative with an eye toward innovation and the adoption of state-of-the-art technology. He was trusted by the staff and he solicited their views on how to provide a flawless customer service and, of course, he was always respectful of their opinions, even when they were contrary to his own.

Felicia Lynn was employed in the financial management and accounting unit of MREC and was in charge of billing and accounts receivable. She too was well liked by the members of the cooperative and especially for those who still chose to pay their bills in person, she exuded congeniality.

Specifically, as Felicia, used to say, "The bills are due on the fifteenth of each month and with all the traffic, it gets really hectic around the office." Ellen Wiley, the company receptionist, greeted those who were coming in and leaving the corporate office with a genuine politeness and caring concern. 
In short, as Derek Spiegel often stated, "If first impressions create indelible corporate images, Ellen is the best person in the world to have at the front desk in the office."

Today, however, her customer orientation took on a new face. Director Spiegel observed Ellen dealing with the "walk-ins" in her normal courteous manner, but at the end of the business transaction she would give the women customers a copy a Debbie Green's Beauty Supply Catalogue. At first, he thought little of what might be a friendly exchange between familiar friends, but it became evident that there was more to it than met the eye, especially when she handed the customer a Debbie Green order blank and a catalog for future purchases. Once more, Lar Spiegel calculated that it must just be a friendly exchange, after all, "...neighbors will be neighbors."

A week or so later, a phone call was transferred to Derek Spiegel's office. A customer wanted to place an order for Debbie Green products and Ellen was not in the office. Spiegel was both astonished and bewildered at what he had just heard and informed the caller that she must have the wrong number or information and that she had reached Morningside Rural Electrical Cooperative, not a beauty supply outlet. The caller was persistent and identified herself as Mrs. Joseph Ruppert and that she knew the difference between an electric utility and a beauty supply store and that she had intentionally called Felicia, as she had often done on other occasions. She desperately needed to place an order for the two skin creams she regularly used.

Spiegel was arrestingly flabbergasted at what had just transpired and when the call ended he went to Felicia's office and indicated that he needed her to come to his office immediately and talk about the business she was operating from the corporate office. Given their respective personalities, Spiegel and Felicia were cordially open and honest with one another. Felicia explained that economic times were tough and as a single parent with three children under the age of eighteen and the middle child having a severe case of autism, she was having a difficult time keeping her "...head above the water." She further explained that she started selling Debbie Green products to augment and supplement her "meager income," and that it was convenient for her customers to have "one-stop" shopping. That is, they could pay their utility bill and pick up their personal supplies at the same time. "Anyway," Felicia explained, "I perform my job-related duties and responsibilities with care and this side-line does not interfere with getting my work done." Then, as if her justification had not enough solvency, she added in a somewhat defensive manner, "Others in the office are selling 'Miles for Dollars' in their walks or races for this and that cure, and every year the scouts sell their tins of popcorn and their variety of cookies in the office."

Derek Spiegel was not amused by Felicia's reaction to his oral reprimand and told her that the business she was conducting from the office must end immediately. Felicia agreed and in a humble demeanor thanked Spiegel for the meeting and apologized for her indiscretion and for any embarrassment it brought to the organization. Since old habits and practices are hard to stop, her customer based continued to call Felicia at work and attempted to place their orders. Felicia told them she would call back after work and that she had been disciplined for selling Debbie Green from her office. She asked the customers to understand her precarious situation and advised them in her always friendly manner, that she would continue to be attentive to their personal grooming and other cosmetic needs.

Later, Spiegel told the members of the board of directors that "office politics" do not get resolved easily or quickly. To further complicate matters, several board members had already received compliments from customers who explained how convenient it was to pay the utility bill and not have to go through the "hassle" of running yet another errand. One of the more senior board members stated, "It was not a big deal," and said, "My wife picks up Debbie Green products from the cooperative's office when her order arrives." In response, Derek Spiegel emphasized that he had asked Felicia to end the business at the office at once. He said, "Our business is electricity and not beauty products and I cannot permit Felicia to engage in conduct that would be denied other workers." Last, another board member said, "Flexibility should be practiced in employee relations whenever possible and as the director he may have been heavy-handed in the way he treated a trusted and loyal worker."

Director Spiegel reflected on what he had learned from the board and was surprised at how permissive they seemed to be. He was happy the day was ending and as he drove into his cul-de-sac, to his surprise and anguish, he saw Felicia dropping off products that had been ordered by his wife. Now, he thought, how twisted fate can become, and wondered if this was an issue on which he should literally "fall on his sword" or formulate a more acceptable policy of selling products or services while at work. 
Now, in a state of bewilderment, Spiegel went to the website of the Society for Human Resource Management [http://www.shrm.org] and downloaded their Model Solicitation Policy, as shown in Exhibit 1. He realized that developing a solicitation policy was more complicated than he first thought. He had to consider a host of topics that surpassed his initial concerns, such as, electronic announcements, the general distribution or posting of literature, and that former "...employees are not permitted onto Company property except for official Company business." Although SHRM was one of his favorite reference points when researching general personnel related policies, he wondered if it might have overstated the specificity that should be included in MREC's solicitation policy.

\section{Exhibit 1: Model Solicitation Policy}

\section{Policy Statement:}

COMPANY ABC prohibits the solicitation, distribution and posting of materials on or at Company property by any employee or non-employee, except as may be permitted by this policy. The sole exceptions to this policy are charitable and community activities supported by Company $\mathrm{ABC}$ management and Company-sponsored programs related to Company ABC products and services.

\section{PROVISIONS:}

Non-employees may not solicit employees or distribute literature of any kind on Company ABC's premises at any time. Employees may only admit non-employees to work areas with management approval or as part of a Company-sponsored program. These visits should not disrupt workflow. The Company ABC employee must accompany the non-employee at all times. Former employees are not permitted onto Company property except for official Company business.

Employees may not solicit other employees during work times, except in connection with a Company approved or sponsored event.

Employees may not distribute literature of any kind during work times, or in any work area at any time, except in connection with a Company-sponsored event.

The posting of materials or electronic announcements are permitted with approval from Human Resources.

Violation of this policy should be reported to Human Resources

Source: Society for Human Resource Management, http://www.shrm.org/TemplatesTools/Samples/Policies/Pages/CMS 000636.aspx

\section{Questions and Instructions}

1. Please analyze the statement of justification that Felicia Lynn gave Derek Spiegel for conducting Debbie Green product transactions in the rural electric cooperatives office. Please provide the merits and problems of her defense.

2. How well do you think Derek Spiegel, the experienced and understanding executive director, did in counseling and disciplining Felicia Lynn? Please explain what you would have said and done either similarly or differently than Spiegel and why? Please elaborate.

3. The Morningside Rural Electrical Cooperative would benefit from having a clear, workable, policy concerning "solicitation" in the workplace. Please check with at least two non-profit, private and public organizations and determine what their respective policies are on this topic. Then, prepare a written statement in which the policies are quoted and evaluated in relation to their strengths and weaknesses and distribute to your colleagues in class. Next, please discuss the observations made by the other members of the class.

4. Attached as Exhibit 1, Model Solicitation Policy, illustrates what may be included as a range of appropriate topics and areas of concern for a solicitation policy. Please note that it goes far beyond selling items in the workplace to other employees, customers, or vendors and also entails political party and religious propagation. What do you see as beneficial or problematic with the model solicitation policy? Please explain.

5. Please conduct a web search on solicitation policies in public service or nonprofit organizations and prepare a written policy statement that might be added to MREC's Employee handbook. Indicate the strengths of your policy recommendation and any "gaps" that it might leave unfilled. Please be specific.

\section{Case Title: Always be Selling-Even on the Job \\ Name:}

\section{Case Log and Administrative Journal Entry}


This case analysis and learning assessment may be submitted for either instructor or peer assessment

\section{Case Analysis:}

Major case concepts and theories identified:

What is the relevance of the concepts, theories, ideas and techniques presented in the case to that of public or private management?

Facts - what do we know for sure about the case? Please list.

Who is involved in the case (people, departments, agencies, units, etc.)? Were the problems of an "intra/interagency" nature? Be specific.

Are there any rules, laws, regulations or standard operating procedures identified in the case study that might limit decision-making? If so, what are they?

Are there any clues presented in the case as to the major actor's interests, needs, motivations and personalities? If so, please list them.

\section{Learning Assessment:}

What do the administrative theories present in this case mean to you as an administrator or manager?

How can this learning be put to use outside the classroom? Are there any problems you envision during the implementation phase?

Several possible courses of action were identified during the class discussion. Which action was most practical by the group? Which was deemed most feasible? Based on your personal experience, did the group reach a conclusion that was desirable, feasible, and practical? Please explain why or why not.

Did the group reach a decision that would solve the problem on a short-term or long-term basis? Please explain.

What could you have done to receive more learning value from this case?

Source: Case Log and Administrative Journal Entry reprinted with permission, Millennium HRM Press, Inc.

\section{References}

"Use Policies to Properly Limit Selling or Soliciting on Work Time," https://www.bizfilings.com/toolkit/researchtopics/office-hr/use-policies-to-properly-limit-selling-or-soliciting-on-work-time

"Sample, Employee Handbook, Solicitation, 4.9" http://www.stonetrustinsurance.com/pdfs/LASampleEmployeeHandbookRev08.pdf

Solicitation and Distribution Rules and Their Enforcement Under Attack: NLRB Continues to Narrow Employer Limitations on Workplace Communications By Dale Deitchler https://www.littler.com/files/press/pdf/2014_12_ASAP_Solicitation_Distribution_Rules_Their_Enforcem ent_Under_Attack_NLRB.pdf

"Solicitation," Vanderbilt University Human Resource Policies and Procedures, https://hr.vanderbilt.edu/policies/solicitation.php

"Work Environment," Case Western Reserve University. http://case.edu/finadmin/humres/policies/standards/work_env.html

"Solicitation and distribution Policy, Lincoln financial Group, https://hrdirectdocs.lfg.com/misc/HR/Policies_Procedures/SolicitationandDistribution

C. Thomas Davis .Solicitation And Distribution: Who Can Do What, When And Where? https://ogletree.com/shared-content/content/blog/articles/solicitation-and-distribution-who-can- do-whatwhen-and why 